Supporting Information

\title{
Molecular Recognition of Fluorescent Probe Molecules with Pseudo-Polyrotaxane Nanosheet
}

\author{
Shuntaro Uenuma*, Rina Maeda, Hideaki Yokoyama, and Kohzo Ito*
}

Department of Advanced Materials Science, Graduate School of Frontier Sciences, The University of Tokyo,

Kashiwa City, Chiba 277-8561, Japan

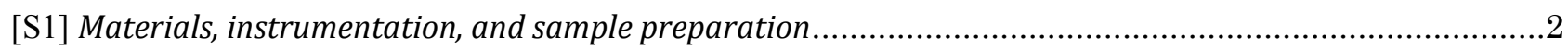

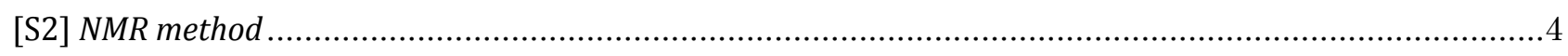

[S3] Effect of EO chains of PPRNS on selective adsorption of dye molecules................................................7

[S4] Effect of the micelles of $\mathrm{COOH}-\mathrm{EO}_{75} \mathrm{PO}_{29} \mathrm{EO}_{75}$ on selective adsorption of dye molecules ........................... 8

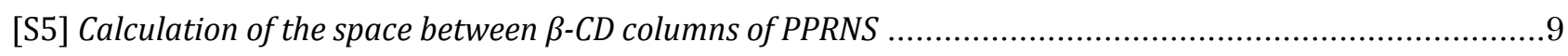

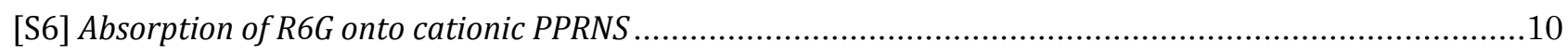

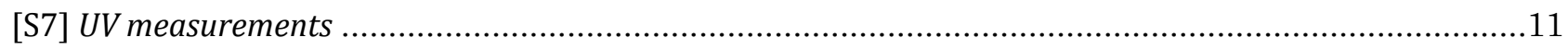

[S8] PPRNS amount in the sample used for ${ }^{1} \mathrm{H} N M R$ and $U V$-vis experiments............................................13

[S9] Absorption of various amounts of dye molecules by PPRNS ............................................................ 14 
[S1] Materials, instrumentation, and sample preparation

\section{Materials}

$\beta$-CD, $\mathrm{EO}_{75} \mathrm{PO}_{29} \mathrm{EO}_{75}$ (Pluronic F68), $\mathrm{D}_{2} \mathrm{O}$ (99.9 atom\%, made by ISOTEC Corporation), rhodamine 6G (R6G), rhodamine 123 (R123), rhodamine 590 (R590), uranine, rhodamine B (RB), rhodamine 640 (R640), 3-(trimethylsilyl)-1-propane sulfonic acid- $d_{6}$ sodium salt (DSS- $d_{6}$ ) $\mathrm{D}_{2} \mathrm{O}$ solution were purchased from Fujifilm Wako Pure Chemical Corporation and Sigma-Aldrich. All reagents were used as received.

\section{Instrumentation}

${ }^{1} \mathrm{H}$ NMR measurements were performed using a JEOL JNM-AL400 instrument. UV-vis absorption spectra were recorded with a Shimadzu UV-3150 spectrophotometer using a quartz cuvette $(t=3.5 \mathrm{~mm}, w=12.5 \mathrm{~mm}, L=45 \mathrm{~mm}$, optical path length $=1 \mathrm{~mm}$ ). The wavelength range for measurement was $300-800 \mathrm{~nm}$. Optical and fluorescence microscopy were performed using a Nikon ECLIPSE Ts2R with a Nikon DS-Fi3 camera. The excitation wavelength was $470 \mathrm{~nm}$ and the emission at $510 \mathrm{~nm}$ was monitored.

Synthesis of $\mathrm{COOH}-\mathrm{EO}_{75} \mathrm{PO}_{29} \mathrm{EO}_{75}$

$\mathrm{COOH}-\mathrm{EO}_{75} \mathrm{PO}_{29} \mathrm{EO}_{75}$ was synthesized by the method reported in our previous paper.[1] The modification ratio was $90 \%$.

Synthesis of $\mathrm{NH}_{2}-\mathrm{EO}_{75} \mathrm{PO}_{29} \mathrm{EO}_{75}$

$\mathrm{NH}_{2}-\mathrm{EO}_{75} \mathrm{PO}_{29} \mathrm{EO}_{75}$ was synthesized following the method previously reported by Fujita et al. ${ }^{[2]} \mathrm{EO}_{75} \mathrm{PO}_{29} \mathrm{EO}_{75}(5.00 \mathrm{~g}$, $0.6 \mathrm{mmol}$ ) was dissolved in THF (50 mL) and 1,1'-carbonyldiimidazole (CDI: $1.06 \mathrm{~g}, 6.54 \mathrm{mmol}$ ) was dissolved in THF (31.5 mL). A THF solution of $\mathrm{EO}_{75} \mathrm{PO}_{29} \mathrm{EO}_{75}$ was added dropwise to the CDI solution and stirred overnight under argon atmosphere. The CDI-activated $\mathrm{EO}_{75} \mathrm{PO}_{29} \mathrm{EO}_{75}$ was added dropwise to ethylene diamine (65.4 mmol) and stirred for $3 \mathrm{~h}$. The solvent was removed by evaporation, and the crude product dissolved in water and dialyzed for $2 \mathrm{~d}$. After the aqueous solution was freeze-dried, the product was obtained as a white powder (4.60 g). The modification ratio of the end group of $\mathrm{EO}_{75} \mathrm{PO}_{29} \mathrm{EO}_{75}$ was analyzed by ${ }^{1} \mathrm{H}$ NMR spectrometry (Figure S1), which was $93 \%$. SEC traces indicate that the polymer backbone is not decomposed (Figure S2).
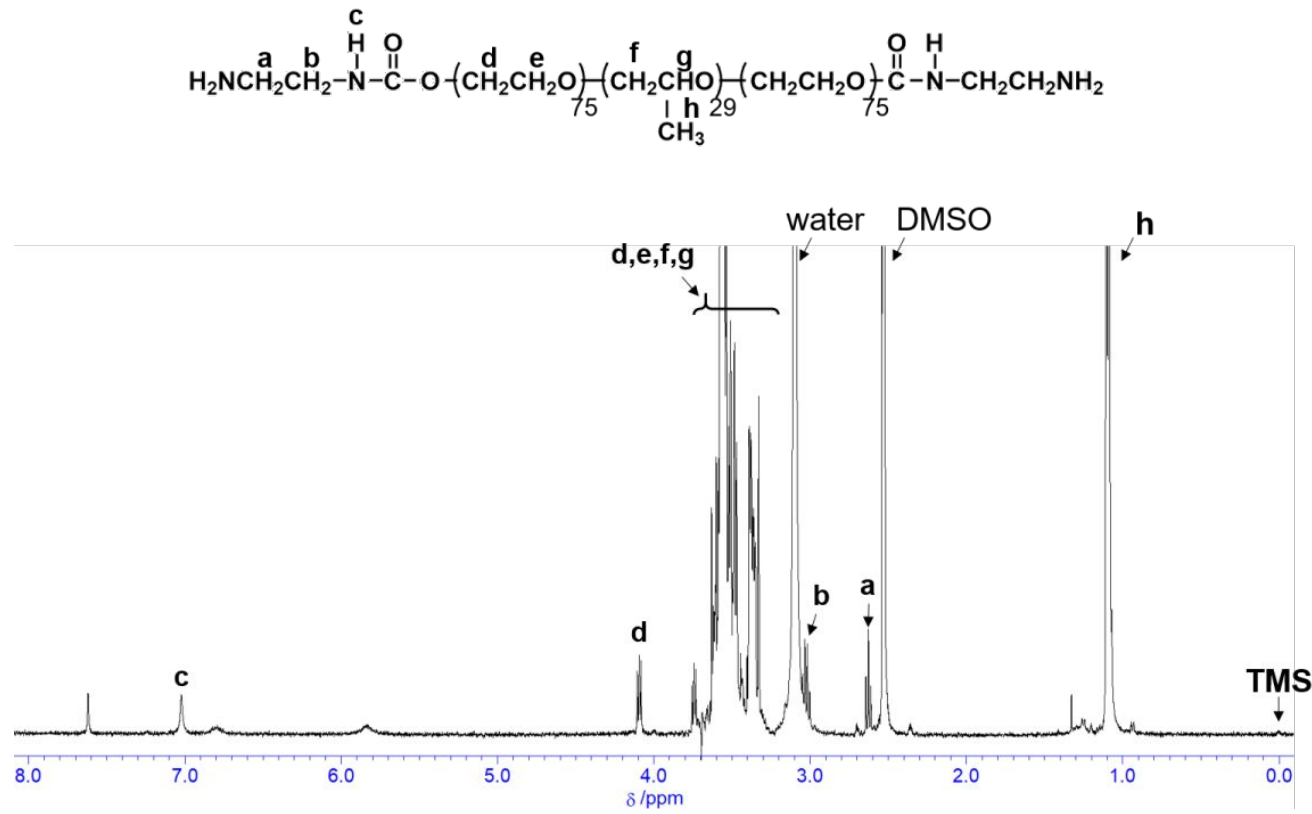

Figure S1. ${ }^{1} \mathrm{H}$ NMR spectrum of $\mathrm{NH}_{2}-\mathrm{EO}_{75} \mathrm{PO}_{29} \mathrm{EO}_{75}$ in DMSO- $d_{6}$. 


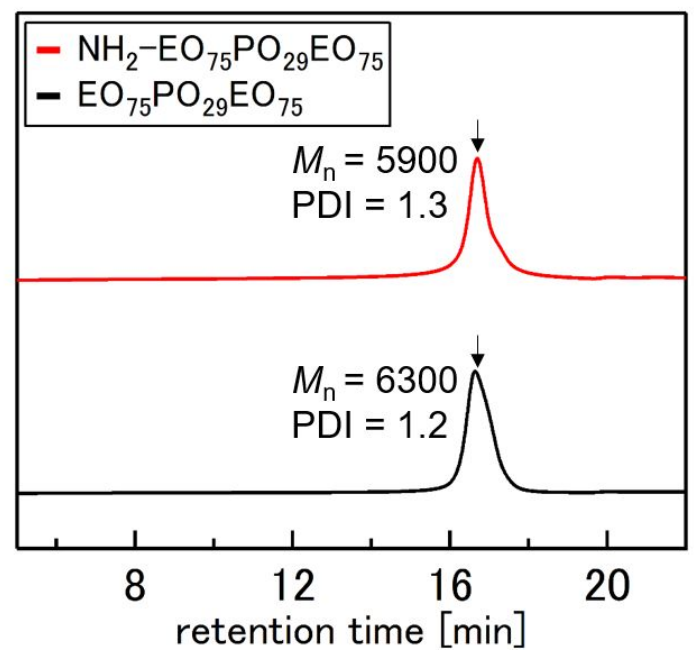

Figure S2. SEC traces of $\mathrm{EO}_{75} \mathrm{PO}_{29} \mathrm{EO}_{75}$ and $\mathrm{NH}_{2}-\mathrm{EO}_{75} \mathrm{PO}_{29} \mathrm{EO}_{75}$ (eluent: $\mathrm{CHCl}_{3}$ ).

\section{Preparation of PPRNS}

The procedure follows that reported in a previous paper ${ }^{[3]}$ with slight modifications. $\beta$-CD (90.0 mg) was dissolved in $5 \mathrm{~mL}$ of $\mathrm{D}_{2} \mathrm{O}$ at $60^{\circ} \mathrm{C}$ for $30 \mathrm{~min}$ (as discussed below, $\beta$-CD contained $17.7 \mathrm{wt} \%$ of water. This means that as $90 \mathrm{mg}$ of $\beta$ $\mathrm{CD}$ was weighed, the real $\beta$-CD amount was $74.1 \mathrm{mg}$ ). After the solution was cooled to room temperature using a water bath, $20.0 \mathrm{mg}$ of $\mathrm{COOH}-\mathrm{EO}_{75} \mathrm{PO}_{29} \mathrm{EO}_{75}$ and $\mathrm{NH}_{2}-\mathrm{EO}_{75} \mathrm{PO}_{29} \mathrm{EO}_{75}$ were added to the solution.

For ${ }^{1} \mathrm{H}$ NMR experiments, the mixed $\beta$-CD and $\mathrm{COOH}-\mathrm{EO}_{75} \mathrm{PO}_{29} \mathrm{EO}_{75}$ solution was poured into an NMR tube. ${ }^{1} \mathrm{H}$ NMR spectra were recorded after each complexation. For the experiment of the fluorescent probe absorption by PPRNS, a PPRNS water dispersion that was complexed for $10 \mathrm{~d}$ was used.

\section{Preparation of PPRNS samples for fluorescent probe absorption experiments}

Each fluorescent probe $\mathrm{D}_{2} \mathrm{O}$ solution was prepared using a concentration of $2 \mathrm{mg} / \mathrm{mL}$. Next, $300 \mu \mathrm{L}$ of the PPRNS water dispersion complexed for $10 \mathrm{~d}, 30 \mu \mathrm{L}$ of the fluorescent probe solution, and $270 \mu \mathrm{L}$ of $\mathrm{D}_{2} \mathrm{O}$ were mixed. By changing the amount of the fluorescent probe solution and $\mathrm{D}_{2} \mathrm{O}$, a PPRNS $\mathrm{D}_{2} \mathrm{O}$ dispersion with a fluorescent probe concentration of $0.10 \mathrm{mg} / \mathrm{mL}, 0.15 \mathrm{mg} / \mathrm{mL}, 0.20 \mathrm{mg} / \mathrm{mL}$, and $0.40 \mathrm{mg} / \mathrm{mL}$ and a fixed PPRNS concentration were prepared. The measurements $\left({ }^{1} \mathrm{H}\right.$ NMR, fluorescent microscopy, and UV-vis) were performed after the sample was aged for 30 min because the R6G absorption onto PPRNS reached equilibrium in less than $30 \mathrm{~min}$. 


\section{[S2] NMR method}

\section{Confirmation that the integral derived from water is constant}

${ }^{1} \mathrm{H}$ NMR measurements were performed using the $\mathrm{D}_{2} \mathrm{O}$ solution containing $1 \mathrm{vol} \%$ of DMSO at 0,52 , and $189 \mathrm{~h}$ after the first measurement. By setting the integral of the DMSO peak to 100, we obtained the integrals of the water peak at the mentioned time, which were 29.7, 29.2, and 29.3, respectively. This experiment confirmed that the water integral was constant and that the water peak can be used as a calibration peak unless the cap of NMR tube is removed.

\section{Coaxial NMR tube and its quantitative analysis capability}

To avoid the interaction between the standard molecules and the complexation of $\beta$ - $C D$ with the axis polymer, we used a coaxial NMR tube (Figure S3). A volume of $200 \mu \mathrm{L}$ standard reagent ( $\mathrm{D}_{2} \mathrm{O}$ solution of DSS- $d_{6}$ or maleic acid) was poured into an inner tube and $500 \mu \mathrm{L}$ of sample solution for complexation was placed in an outer tube.

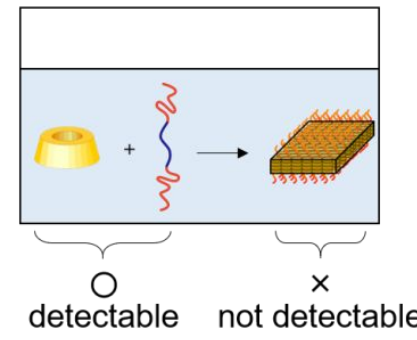

(a)

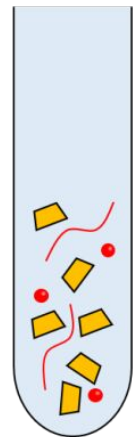

(b)

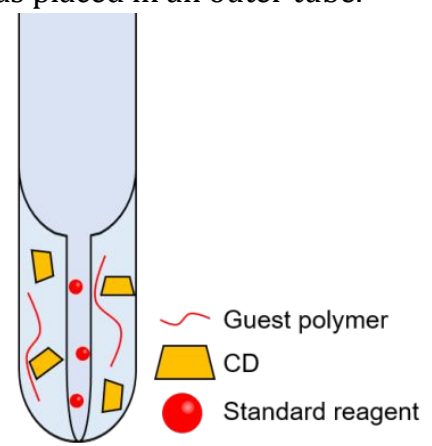

(c)

Figure S3. Schematic illustration of the ${ }^{1} \mathrm{H}$ NMR experiment used in this study. (a) Solute molecules, which have a high molecular mobility, are detectable by solution state ${ }^{1} \mathrm{H}$ NMR. On the other hand, particles with a diameter larger than molecules have low mobility. Therefore, the peak derived from large particles cannot be observed in the profile obtained by the solution NMR experiment. (b) To quantitatively analyze the molar number of molecules in the solution, a standard reagent is necessary. However, the standard reagent might affect the PPRNS structure. (c) To avoid the interaction between the standard molecules and complexation of $\beta$-CD with the axis polymer, we used a coaxial NMR tube.

We tested the quantitative analysis of a coaxial NMR tube. The procedure was as follows: $500 \mu \mathrm{L}$ of $\mathrm{D}_{2} \mathrm{O}$ and $200 \mu \mathrm{L}$ of acetone were mixed and placed in the inner tube. Then, $500 \mu \mathrm{L}$ of $\mathrm{D}_{2} \mathrm{O}$ and $50 \mu \mathrm{L}$ of DMSO were mixed. The concentration of this DMSO $/ \mathrm{D}_{2} \mathrm{O}$ solution was defined as $C_{\mathrm{DMSO}}$. This solution was diluted with $\mathrm{D}_{2} \mathrm{O}$, and samples with the concentrations of $C_{\mathrm{DMSO}} / 2$ and $C_{\mathrm{DMSO}} / 8$ were prepared.

The ${ }^{1} \mathrm{H}$ NMR spectra are shown in Figure S4. The integrals of the DMSO peak in the sample with the concentration of $C_{\text {DMSO }}$ is defined as 100 for convenience. The integrals of the acetone peak $(2.1 \mathrm{ppm}, 19.95)$ were obtained as a relative value. In the case of the profiles of the sample with the concentration of $C_{\mathrm{DMSO}} / 2$ and $C_{\mathrm{DMSO}} / 8$, the integrals of the DMSO peak were set to 50 and 12.5. Then, the constant value of the integrals of the acetone peak were determined. This test demonstrates that the standard peak can be introduced into the ${ }^{1} \mathrm{H}$ NMR spectrum, avoiding the interaction between the standard reagent and the sample during analysis. 


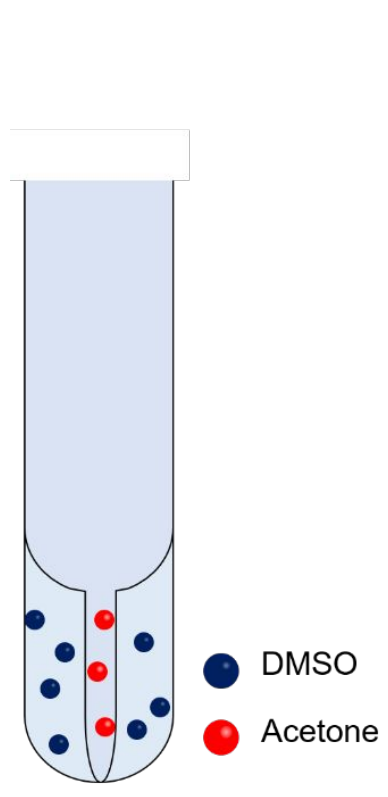

(a)

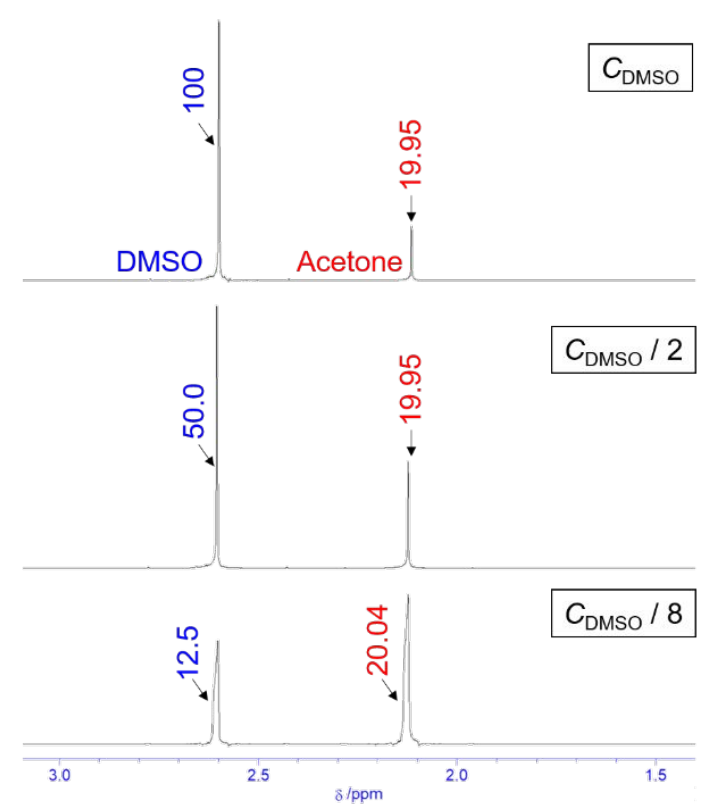

(b)

Figure S4. (a) Schematic illustration of the DMSO and acetone $\mathrm{D}_{2} \mathrm{O}$ solutions poured into the coaxial NMR tube. (b) ${ }^{1} \mathrm{H}$ NMR spectra of the DMSO $\mathrm{D}_{2} \mathrm{O}$ solution with the concentration of $C_{\mathrm{DMSO}}, C_{\mathrm{DMSO}} / 2$, and $C_{\mathrm{DMSO}} / 8$ calibrated with acetone placed in an inner tube.

\section{Water amount absorbed into the $C D$}

It is known that $\beta$-CD contains crystal water. ${ }^{[4]}$ Using a coaxial NMR tube with a standard sample (maleic acid, 6.2 $\mathrm{ppm})$, we calculated the amount of water absorbed into $\beta$-CD. The procedure was as follows: $\beta$-CD $(11.9,9.87,7.88$, and $6.10 \mathrm{mg}$ ) was dissolved in $1 \mathrm{~mL}$ of $\mathrm{D}_{2} \mathrm{O}$. Then, these solutions were placed in the outer tubes of the coaxial NMR tube. Maleic acid $\mathrm{D}_{2} \mathrm{O}$ solution was poured into the inner tube.

The integrals of the water and $\beta$-CD peak linearly increased with increasing $\beta$-CD amount (Figure S5a and $\mathrm{b}$ ) according to equations $y=24.673 x+1063.5$ and $y=6.1726 x$, respectively. From the ratio of their slope it was calculated that the molar fraction of water in $\beta$-CD was $93.1 \mathrm{~mol} \%$. This value can be converted to the weight fraction of water in $\beta$-CD, which was $17.7 \mathrm{wt} \%$. This is reasonable because it was reported that the water content in a commercial $\beta$-CD is approximately $14-15 \mathrm{wt} \% \cdot{ }^{[4]}$ Our result means that when $18.0 \mathrm{mg} \beta$-CD is weighed, the actual weight of $\beta$-CD is $14.8 \mathrm{mg}$. We used this value to calculate the amount of formed PPRNS.

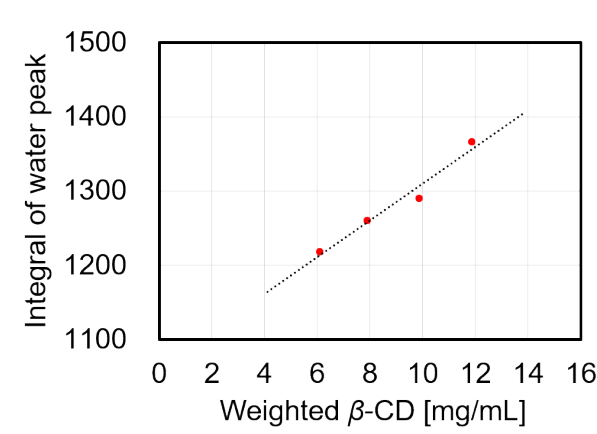

(a)

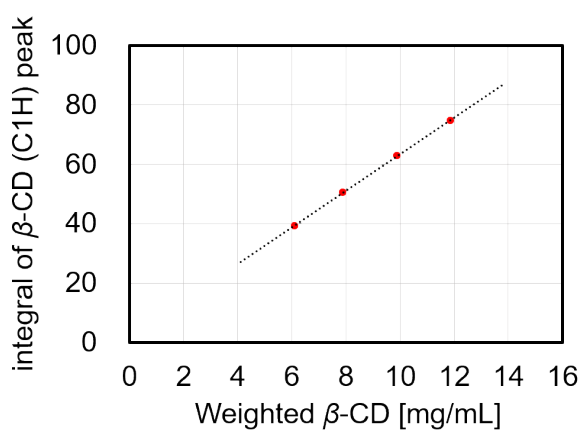

(b)

Figure S5. (a) Plot of the integral derived from $\mathrm{H}_{2} \mathrm{O}$ and from (b) $\mathrm{C} 1 \mathrm{H}$ of $\beta$-CD with respect to the weighted concentration of $\beta$ CD. 


\section{Calibration of standard peak of sample in inner tube}

Weighing an amount of $11.9 \mathrm{mg} \beta$-CD and dissolving it in $1 \mathrm{~mL}$ of $\mathrm{D}_{2} \mathrm{O}$ means that the real concentration of $\beta$-CD is 9.77 $\mathrm{mg} / \mathrm{mL}(8.60 \mathrm{mmol} / \mathrm{L})$. One $\beta$-CD molecule contains seven $\mathrm{C} 1 \mathrm{H}$ and by calculating the integral of the $\mathrm{C} 1 \mathrm{H}$ peak as $8.60 \times$ $7=60.23 \mathrm{mmol} / \mathrm{L}$, the standard peak of the maleic acid in the inner tube was calibrated to a value of 79.47. Using this value, the absolute proton concentration of the sample in the outer tube was determined. This method was applied not only to maleic acid but also to DSS- $d_{6}(0 \mathrm{ppm})$. We used a calibrated inner tube containing DSS- $d_{6}$ (the integral of DSS- $d_{6}$ peak was 2.92) to investigate which chemical groups of R6G and uranine interact with the PPRNS (Figure 2 in the manuscript).

\section{Absorption timescales of R6G onto PPRNS}

The Langmuir absorption isotherm can be used to determine the thermal equilibrium between the absorption onto PPRNS and its association with the R6G solution. The timescale of the R6G absorption onto PPRNS was established by measuring the ${ }^{1} \mathrm{H}$ NMR spectrum of the PPRNS $\mathrm{D}_{2} \mathrm{O}$ dispersion containing $0.2 \mathrm{mg} / \mathrm{mL}$ R6G at 30 min and $1 \mathrm{~d}$ after the R6G addition (Figure S6). It was observed that the integrals of both ${ }^{1} \mathrm{H}$ NMR spectra were similar. This suggests that the absorption and association of R6G reaches equilibrium in less than $30 \mathrm{~min}$. In this study, all experiments using fluorescent probes (fluorescent microscopy, ${ }^{1} \mathrm{H}$ NMR, and UV-vis ) were performed in between $30 \mathrm{~min}$ and $1 \mathrm{~d}$.

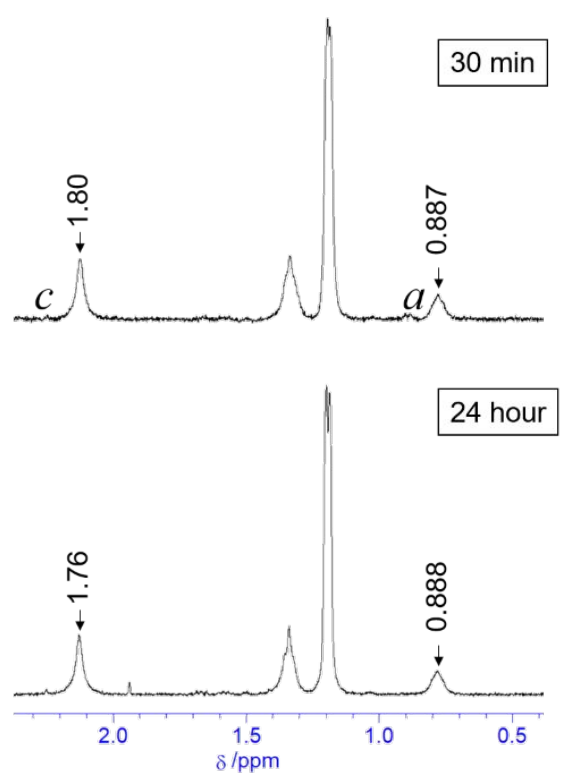

Figure S6. ${ }^{1} \mathrm{H}$ NMR spectra of the PPRNS $\mathrm{D}_{2} \mathrm{O}$ dispersion containing $0.2 \mathrm{mg} / \mathrm{mL}$ R6G at $30 \mathrm{~min}$ and $1 \mathrm{~d}$ after the R6G addition The integrals of chemical groups $a$ and $c$ of R6G (indicated in Figure 2 in the manuscript) were identical. 
[S3] Effect of EO chains of PPRNS on selective adsorption of dye molecules

To investigate the effect of EO chains on the selective adsorption of dye molecules, we prepared the inclusion complex crystal between $\beta$-CD and $\mathrm{PO}_{13}\left(\beta C D / \mathrm{PO}_{13}\right.$, the subscript denotes the number of repeating units of $\mathrm{PO}$ ), which has no EO chains. The preparation method and the SEM image were reported in our previous paper. ${ }^{[5]}$ The optical microscope image of $\beta C D / \mathrm{PO}_{13}$ is shown in Figure $\mathrm{S} 7 \mathrm{a}$. When the $\mathrm{R} 6 \mathrm{G}$ was added to the dispersion of this sample, the R6G was adsorbed onto the $\beta \mathrm{CD} / \mathrm{PO}_{13}$ crystal (Figure S7b). In contrast, uranine was not adsorbed onto the $\beta C D / P O_{13}$ crystal (Figure S7c). This clear difference indicates that EO chains does not affect the selective adsorption of dye molecules.
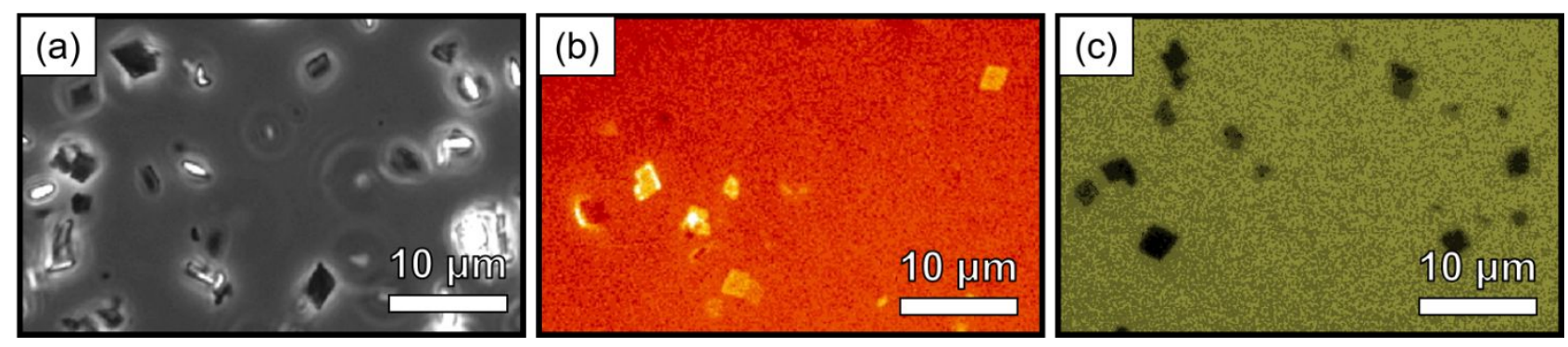

Figure S7. (a) Optical microscope image of $\beta \mathrm{CD} / \mathrm{PO}_{13}$. (b) Fluorescence microscope image of $\beta \mathrm{CD} / \mathrm{PO} \mathrm{O}_{13}$ with $0.1 \mathrm{mg} / \mathrm{mL}$ of R6G. (c) Fluorescence microscope image of $\beta \mathrm{CD} / \mathrm{PO}_{13}$ with $0.1 \mathrm{mg} / \mathrm{mL}$ of uranine. 
[S4] Effect of the micelles of $\mathrm{COOH}-\mathrm{EO}_{75} \mathrm{PO}_{29} \mathrm{EO}_{75}$ on selective adsorption of dye molecules

To confirm the contribution of the micelles of $\mathrm{COOH}-\mathrm{EO}_{75} \mathrm{PO}_{29} \mathrm{EO}_{75}$ to the selective adsorption of dye molecules, at first, we tried making the PPRNS dispersion without $\mathrm{COOH}-\mathrm{EO}_{75} \mathrm{PO}_{29} \mathrm{EO}_{75}$, and then checked the adsorption behaviors of dye molecules.

\section{Preparation of $\mathrm{COOH}-\mathrm{EO}_{75} \mathrm{PO}_{29} \mathrm{EO}_{75}$-free PPRNS dispersion}

We tried removing $\mathrm{COOH}-\mathrm{EO}_{75} \mathrm{PO}_{29} \mathrm{EO}_{75}$ in the PPRNS dispersion by centrifugation and washing them with $\beta$-CD saturated solution (Figure S8a). PPRNS could be dispersed in saturated $\beta$-CD solution, and $\beta$-CD solution could suppress the dissolution of PPRNS. ${ }^{1} \mathrm{H}$ NMR experiments for the aliquots obtained at each washing step could detect the $\mathrm{COOH}$ $\mathrm{EO}_{75} \mathrm{PO}_{29} \mathrm{EO}_{75}$ in the supernatant by analyzing the peak integrals of methyl protons of PPO that is observed at 1 ppm (Figure S8b). The peak of PPO methyl group of over twice washed samples almost disappeared. This indicates that the $\mathrm{COOH}-\mathrm{EO}_{75} \mathrm{PO}_{29} \mathrm{EO}_{75}$ was removed.

Next R6G and uranine were added to the $\mathrm{COOH}-\mathrm{EO}_{75} \mathrm{PO}_{29} \mathrm{EO}_{75}$-free PPRNS dispersion. Then, we obtained the same results of fluorescence microscope observation (R6G was absorbed onto PPRNS and uranine was not, Figure S9) as the results before washing. This suggests that the existence of the micelles does not mainly contribute to the selective adsorption of the dye molecules

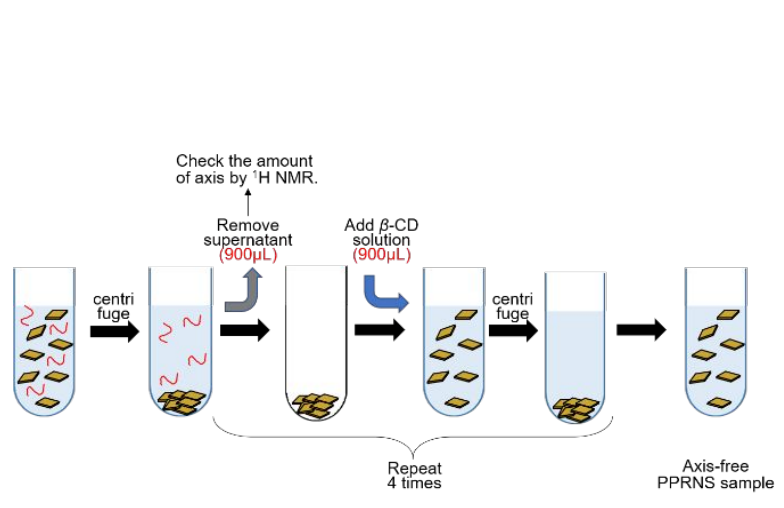

(a)

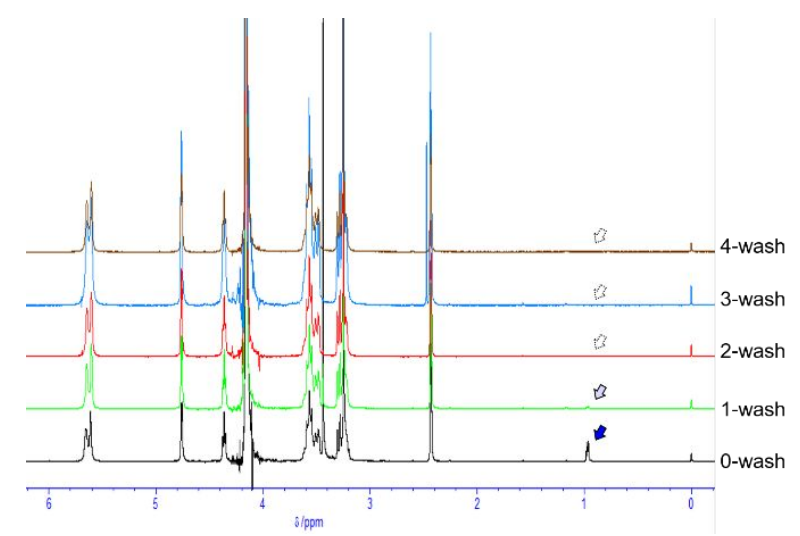

(b)

Figure S8. (a) Schematic illustration of how to remove the axis in supernatant of PPRNS dispersion and (b) ${ }^{1} \mathrm{H}$ NMR spectrum of the aliquots obtained at each washing step.

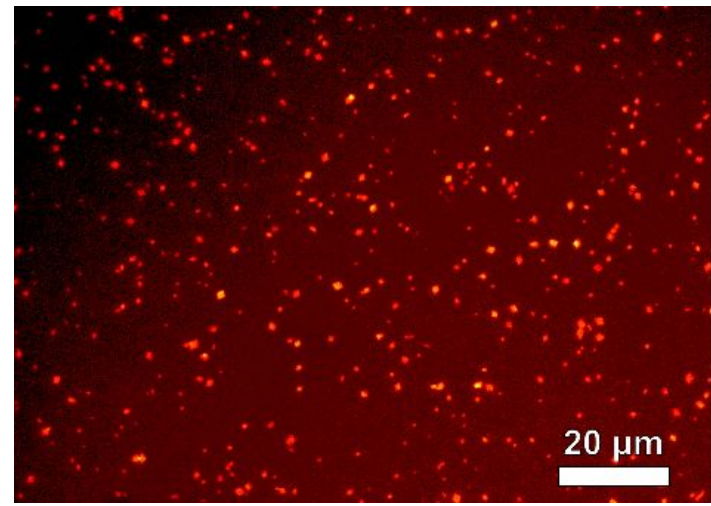

(a)

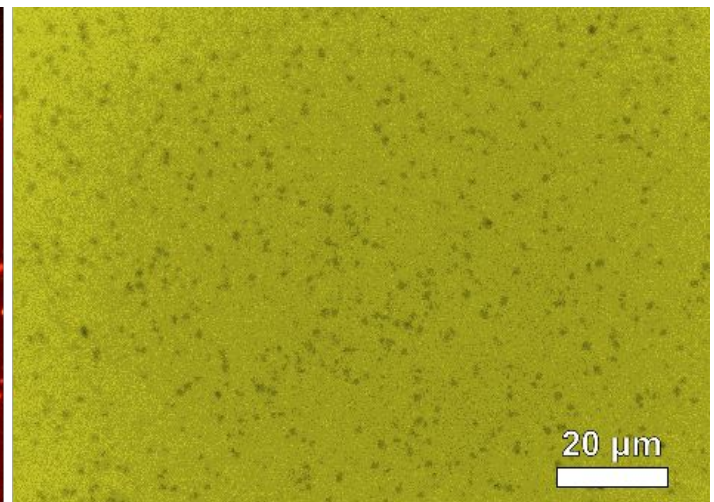

(b)

Figure S9. Fluorescence microscope images of the axis-free PPRNS with $0.1 \mathrm{mg} / \mathrm{mL}$ of (a)R6G and (b) uranine. 
[S5] Calculation of the space between $\beta$-CD columns of PPRNS

The area of space between $\beta$-CD columns could be roughly estimated (Figure S10) by assuming a simple model based on the lattice parameter (monoclinic with $a=1.910 \mathrm{~nm}, b=2.426 \mathrm{~nm}, c=1.568 \mathrm{~nm}, \alpha=\gamma=90^{\circ}$, and $\beta=111^{\circ}$ ) reported in ref [6] and the diameter of $\beta$-CD reported in ref [7] in manuscript. Especially, the diameter of the black circle in Figure $\mathrm{S} 10 \mathrm{~b}$ is $2.46 \AA$. This value is comparable with the size of methyl groups (the length of C-H bond is approximately $1.1 \AA$ ).

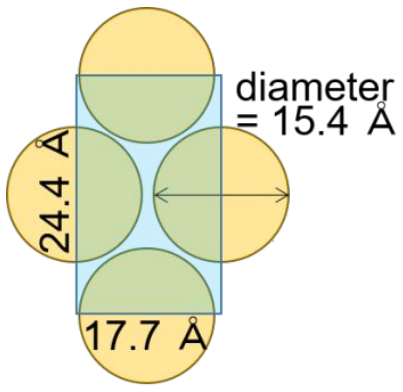

(a)

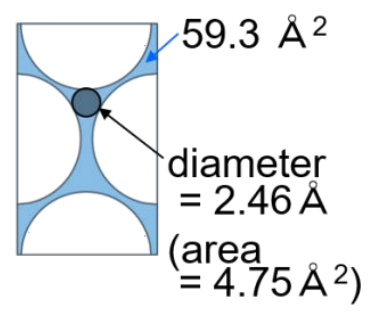

(b)

Figure S10. The calculation of the area of the space between $\beta$-CD columns assuming a simple model based on the lattice parameter (monoclinic with $a=1.910 \mathrm{~nm}, b=2.426 \mathrm{~nm}, c=1.568 \mathrm{~nm}, \alpha=\gamma=90^{\circ}$, and $\beta=111^{\circ}$ ) reported in ref [6] and the diameter of $\beta$-CD reported in ref [7] in manuscript. 


\section{[S6] Absorption of R6G onto cationic PPRNS}

The optical and fluorescent microscopy results for the $\mathrm{NH}_{2}$-PPRNS $\mathrm{D}_{2} \mathrm{O}$ dispersion containing $0.1 \mathrm{mg} / \mathrm{mL}$ of $\mathrm{R} 6 \mathrm{G}$ are shown in Figure S11. These results clearly indicate that a structure similar to that of COOH-PPRNS is formed in the case of $\mathrm{NH}_{2}$-PPRNS, and that $\mathrm{R} 6 \mathrm{G}$ is absorbed by $\mathrm{NH}_{2}$-PPRNS.

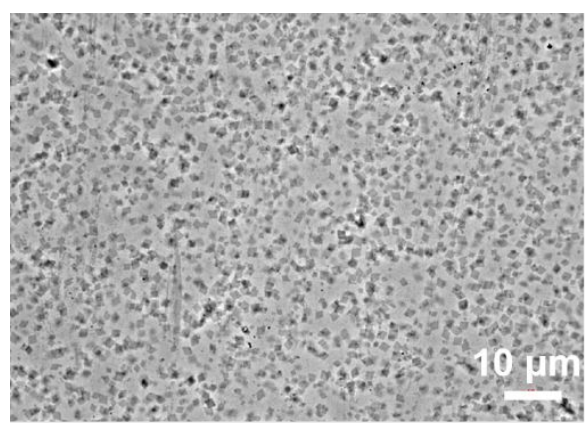

(a)

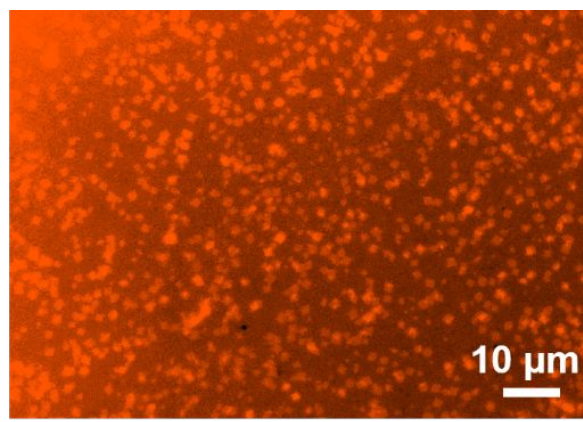

(b)

Figure S11. (a) Optical and (b) fluorescent microscopy of the $\mathrm{NH}_{2}-\mathrm{PPRNS} \mathrm{D}_{2} \mathrm{O}$ dispersion containing $0.1 \mathrm{mg} / \mathrm{mL}$ of $\mathrm{R} 6 \mathrm{G}$. 
Analysis of the R6G amount absorbed onto PPRNS using a UV-vis spectrum

The protocol of the UV experiments is presented in Figure S12a. First, a calibration curve was constructed from the R6G UV-vis spectrum. It is known that the UV spectrum of probe molecules might be changed by forming an inclusion complex with $\beta$-CD in water. ${ }^{[8]}$ Therefore, the supernatant of the COOH-PPRNS $\mathrm{D}_{2} \mathrm{O}$ dispersion was used as a solvent. R6G amounts of $0.0333,0.0667,0.100$, and $0.133 \mathrm{mg} / \mathrm{mL}$ were dissolved in the supernatant, and the UV-vis spectrum measured. The results are shown in Figure S13a. The intensity of the prominent peak at $528.5 \mathrm{~nm}$ was used to generate a calibration curve. The intensities of the peak were plotted as a function of R6G concentration in Figure 4 in the manuscript. The equation $y=14.4 x$ was obtained, where $y$ is the intensity at $528.5 \mathrm{~nm}$ and $x$ is the R6G concentration in $\mathrm{mg} / \mathrm{mL}$.

Next, the R6G amount absorbed by COOH-PPRNS was calculated by analyzing the R6G concentration in the supernatant after collection onto PPRNS (Figure S12b). The procedure is as follows: 0.0333, 0.0667, 0.100, and 0.133 $\mathrm{mg} / \mathrm{mL}$ of R6G was added to the PPRNS $\mathrm{D}_{2} \mathrm{O}$ dispersion. Then, R6G-loaded PPRNS was collected by centrifugation. The R6G concentration in the supernatant was analyzed by measuring the peak intensity at $528.5 \mathrm{~nm}$ (Figure S13b). After the baseline correction, the R6G concentration in the supernatant was calculated using the calibration equation obtained above. Then, the R6G amount absorbed by COOH-PPRNS was calculated by subtracting the R6G concentration in the supernatant from the feed concentration. The results are summarized in Table S1. The R6G concentrations in the solvent and PPRNS were plotted for fitting using the Langmuir absorption isotherm (Figure 4 in the manuscript).

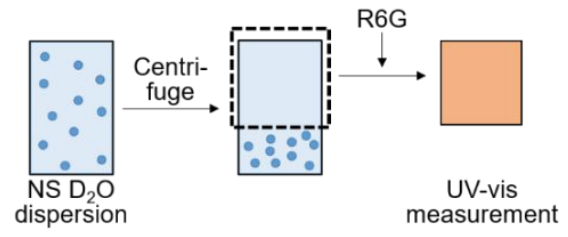

(a)
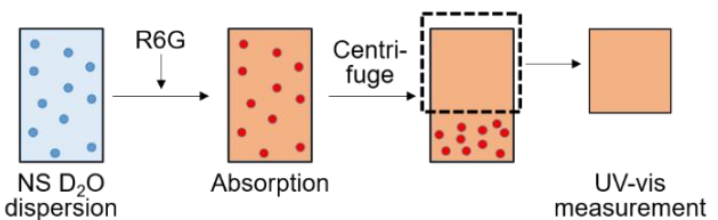

(b)

Figure S12. Protocol for UV measurement. (a) The experiment to generate a calibration curve for R6G and (b) the experiment to determine the amount of R6G absorbed by PPRNS.

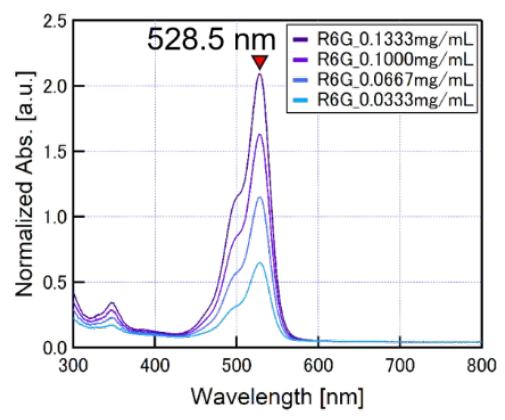

(a)

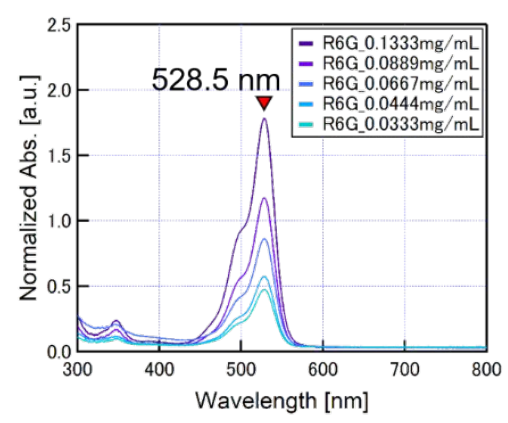

(b)

Figure S13. (a) Original UV spectrum used to generate the calibration curve of R6G. (b) The original UV spectrum collected in the experiments to determine the absorbed R6G amount. The intensities of the peak as function of R6G concentration are plotted in Figure 4 in the manuscript. 
Table S1. Results of the R6G absorption experiments using COOH-PPRNS.

\begin{tabular}{ccccc}
\hline No. & $\begin{array}{c}\text { R6G feed } \\
\text { concentration } \\
{[\mathrm{mg} / \mathrm{mL}]}\end{array}$ & $\begin{array}{c}\text { Int. } \\
(528.5 \mathrm{~nm})^{\mathrm{a}}\end{array}$ & $\begin{array}{c}\text { R6G in solvent } \\
{[\mathrm{mg} / \mathrm{mL}]^{\mathrm{b}}}\end{array}$ & $\begin{array}{c}\text { R6G in NS } \\
{[\mathrm{mg} / \mathrm{mL}]}\end{array}$ \\
\hline 1 & 0.0333 & 0.295 & 0.0205 & 0.0128 \\
2 & 0.0444 & 0.401 & 0.0278 & 0.0166 \\
3 & 0.0667 & 0.705 & 0.0490 & 0.0177 \\
4 & 0.0889 & 0.995 & 0.0691 & 0.0197 \\
5 & 0.1333 & 1.60 & 0.111 & 0.0220 \\
\hline
\end{tabular}

abtained after the baseline correction.

${ }^{b}$ Calculated using the calbration curve.

\section{Analysis of R590 amount absorbed onto PPRNS using a UV-vis spectrum}

The amount of R590 absorbed onto PPRNS was analyzed in the same manner as that for R6G. The original UV spectra are shown in Figure S14. The calculated results are presented in Table S2.

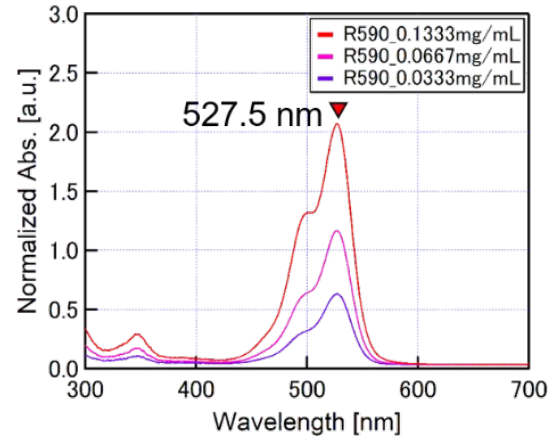

(a)

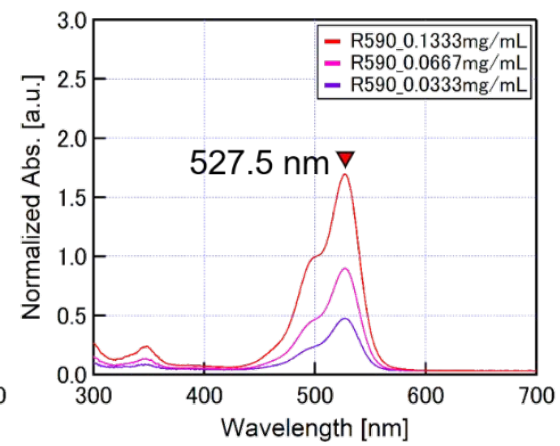

(b)

Figure S14. (a) Original UV spectrum used to generate the calibration curve of R590. (b) Original UV spectrum collected in the experiments to determine the absorbed R590 amount. The intensities of the peak as function of R590 concentration is plotted in Figure 4 in the manuscript.

Table S2. Results of the R590 absorption experiments.

\begin{tabular}{ccccc}
\hline No. & $\begin{array}{c}\text { R590 feed } \\
\text { concentration } \\
{[\mathrm{mg} / \mathrm{mL}]}\end{array}$ & $\begin{array}{c}\text { Int. } \\
(527.5 \mathrm{~nm})^{\mathrm{a}}\end{array}$ & $\begin{array}{c}\text { R590 in solvent } \\
{[\mathrm{mg} / \mathrm{mL}]^{\mathrm{b}}}\end{array}$ & $\begin{array}{c}\text { R590 in NS } \\
{[\mathrm{mg} / \mathrm{mL}]}\end{array}$ \\
\hline 1 & 0.0333 & 0.297 & 0.0206 & 0.0127 \\
2 & 0.0667 & 0.658 & 0.0456 & 0.0211 \\
3 & 0.1333 & 1.516 & 0.1049 & 0.0284 \\
\hline
\end{tabular}

a Obtained after the baseline correction.

b Calculated using the calbration curve. 
[S8] PPRNS amount in the sample used for ${ }^{1} H$ NMR and UV-vis experiments

We checked the amount of $\beta$-CD in PPRNS in the diluted PPRNS sample which was used for the experiment of fluorescent probe absorption. The analysis was conducted measuring ${ }^{1} \mathrm{H}$ NMR spectra using a coaxial tube (Figure S15) at $5 \mathrm{~min}$ and $24 \mathrm{~h}$ after dilution. The $\beta$-CD amounts in the diluted PPRNS were both $2.0 \pm 0.1$ [mmol/L]. It was concluded that the PPRNS dissociation did not proceed within $24 \mathrm{~h}$ after the dilution. Two water peaks were derived from the solutions in the inner and outer tubes.
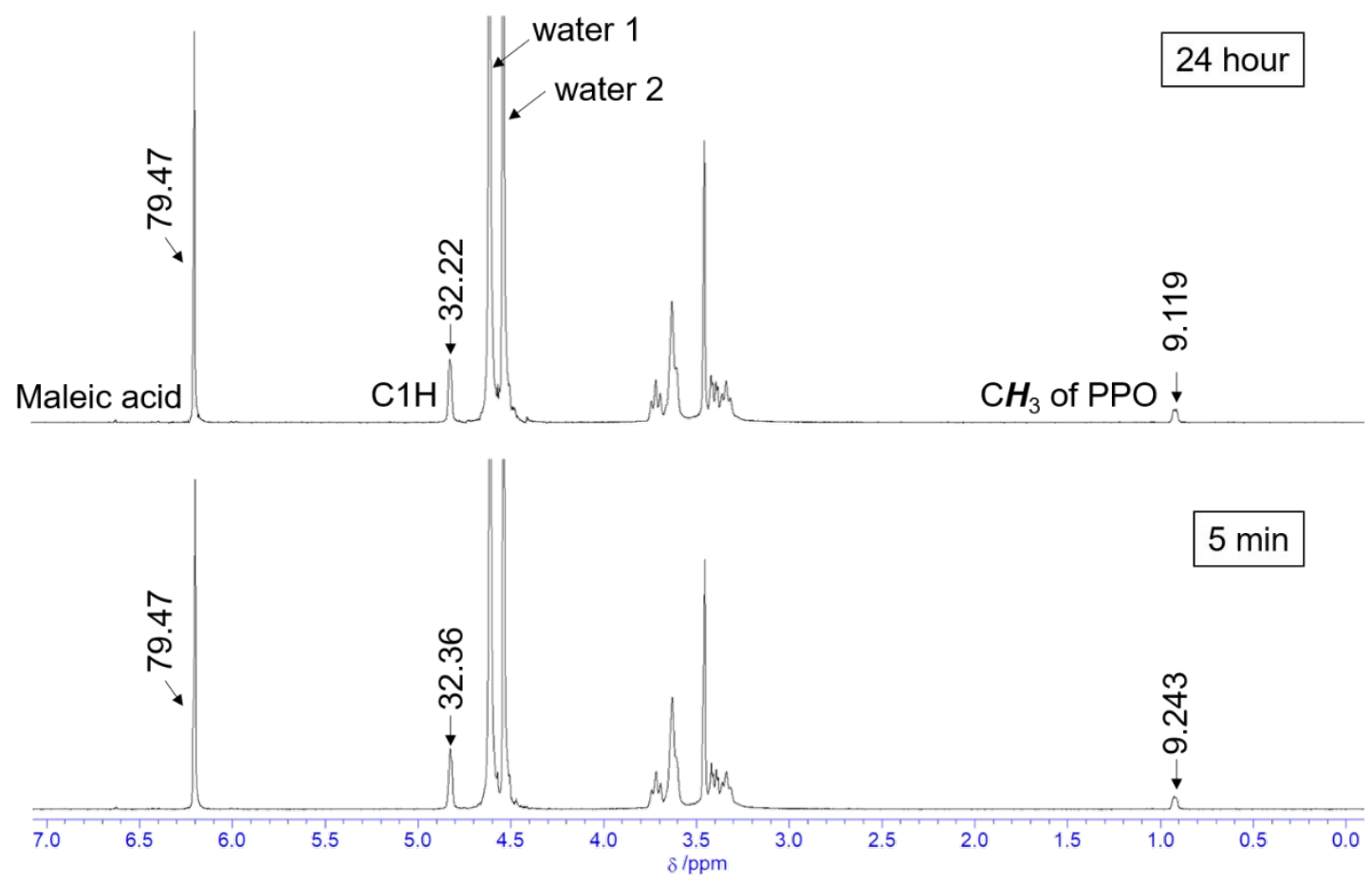

Figure S15. ${ }^{1} \mathrm{H}$ NMR spectra of diluted PPRNS sample at $5 \mathrm{~min}$ and $24 \mathrm{~h}$ after dilution. 
[S9] Absorption of various amounts of dye molecules by PPRNS

Fluorescence microscopy results obtained from the PPRNS $\mathrm{D}_{2} \mathrm{O}$ dispersion which included various R6G concentrations $(0.1,0.2$, and $0.4 \mathrm{mg} / \mathrm{mL})$ are shown in Figure S16. At R6G concentrations of 0.1 and $0.2 \mathrm{mg} / \mathrm{mL}$, bright particles were observed. The particles are darker than the solution in the case of $0.4 \mathrm{mg} / \mathrm{mL}$ of R6G. The fluorescent microscopy experiment also supports that PPRNS can only absorb a specific maximum R6G amount.
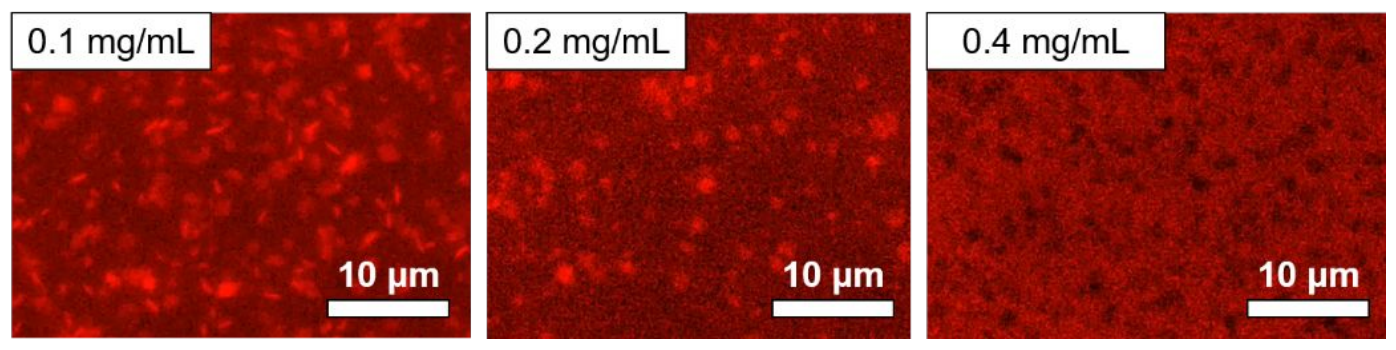

Figure S16. Fluorescence microscopy results for the PPRNS $\mathrm{D}_{2} \mathrm{O}$ dispersions containing $0.1,0.2$, and $0.4 \mathrm{mg} / \mathrm{mL} \mathrm{of} \mathrm{R6G.}$

[1] S. Uenuma, R. Maeda, S. Takahashi, K. Kato, H. Yokoyama, K. Ito, Chem. Lett. 2016, 45, 991-993.

[2] H. Fujita, T. Ooya, N. Yui, Macromolecules 1999, 32, 2534-2541.

[3] S. Uenuma, R. Maeda, H. Yokoyama, K. Ito, Chem. Commun. 2019, 55, 4158-4161.

[4] N. G. Hădărugă, D. I. Hădărugă, H.-D. Isengard, Food Chem. 2012, 132, 1741-1748.

[5] S. Uenuma, R. Maeda, H. Yokoyama, K. Ito, Soft Matter 2020, 16, 9035-9041.

[6] C.-C. Tsai, S. Leng, K.-U. Jeong, R. M. Van Horn, C.-L. Wang, W.-B. Zhang, M. J. Graham, J. Huang, R.-M. Ho, Y. Chen, B. Lotz, S. Z. D. Cheng, Macromolecules 2010, 43, 9454-9461.

[7] J. Szejtli, Chem. Rev. 1998, 98, 1743-1754.

[8] R. N. Dsouza, U. Pischel, W. M. Nau, Chem. Rev. 2011, 111, 7941-7980. 